\title{
The study of internal structure of woven glass and carbon fiber reinforced composite materials with embedded fiber-optic sensors
}

\author{
Grigorii S. Serovaev \\ Institute of Continuous Media Mechanics UB RAS, Russian Federation \\ serovaev@icmm.ru, bttp:/ /orcid.org/0000-0003-0312-8088 \\ Natalia A. Kosheleva \\ Institute of Continuous Media Mechanics UB RAS, Russian Federation \\ kosheleva.n@icmm.ru, bttp://orcid.org/0000-0002-8760-2957
}

\begin{abstract}
In this work, samples from composite materials with embedded optical fibers are investigated. It is known that for unidirectional layered composite materials a distortion of the internal structure and the formation of such technological defect as resin pocket in the region of the embedded optical fiber occur under certain conditions. So it is important to evaluate the change in the internal structure for other types of reinforcement, in particular, woven reinforcement. Analysis of the internal structure of the studied materials with $2 \times 2$ twill weave style was carried out using a digital microscope. In addition, the reflected optical signal from the Bragg gratings after being embedded into the composite material is analyzed.
\end{abstract}

KEYWORDS. Polymer composite material; Woven reinforcement; Singlemode optical fiber; FBG; Sensor embedded in the material.

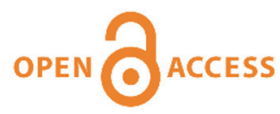

Citation: Serovaev, G., Kosheleva, N., The study of internal structure of woven glass and carbon fiber reinforced composite materials with embedded fiber-optic sensors, Frattura ed Integrità Strutturale, 51 (2020) 225-235.

Received: 06.11 .2019

Accepted: 24.11.2019

Published: 01.01.2020

Copyright: (C) 2020 This is an open access article under the terms of the CC-BY 4.0, which permits unrestricted use, distribution, and reproduction in any medium, provided the original author and source are credited.

\section{INTRODUCTION}

$\mathrm{W}$ ith the constant increase in the use of composite materials in the industry, the share of so-called "smart materials" is also increasing today. Such materials are equipped with different sensing elements which give them the ability to sense the changes of the environmental conditions and to assess their mechanical state and even react to these changes. Among the most promising are the fiber-optic sensors which in combination with widely spread composite materials open new prospects in design and manufacturing of objects of various types of purposes. Thus, it becomes possible to monitor such parameters as strain, temperature and other parameters related to structural health monitoring.

The embedded optical fibers and related technological defects can negatively influence the overall strength and stiffness of the controlled object and can cause dangerous local stress and strain concentrations. According to the known studies, influence of embedded optical fibers varies significantly for different kinds of composite materials, types of external loading, orientation of embedded optical fiber to reinforcing fibers and to the direction of loading. Under static loads an 
insignificant change of stiffness of composite materials with embedded optical fibers is usually observed [1-3]. The decrease in strength is most pronounced under compressive loads compared to tensile loads and when optical fiber is oriented perpendicular to the load direction. A significantly larger negative effect of the embedded optical fibers on the strength of composite materials is observed under fatigue and impact tests in the literature [4-6].

Despite its small size, the diameter of the optical fiber is comparable to the size of a layer of composite material and, if embedded, can cause distortion of the layers. In this case during the manufacturing process of a composite material, this area around the optical fiber becomes filled with epoxy resin. Such technological defect in shape resembles the eye and in literature is called the resin pocket [7]. The size and shape of the resin pocket are determined by many factors, the main of which is the orientation of optical fiber to reinforcing fibers [8]. Among other factors are the mechanical properties of the composite material, the layer's thickness, the number and stacking sequence of the layers, the size of the optical fiber, curing pressure and etc. In the study [9] an approach to determine the shape of a resin pocket, based on numerical finite element modeling of the pressing process in a plane-strain formulation of the theory of elasticity, is considered. Verification of the obtained numerical results with real cross-sectional images of polymer composite material (PCM) samples with embedded optical fiber showed the reliability of this method for determining the shape of the resin pocket. A numerical study of the effect of an embedded optical fiber on a local stress concentration is performed in [10]. The authors proposed a description of the fracture mechanism under tensile and compressive loads which starts in the region of the resin pocket. The study [11] investigated the effect of the resin pocket geometry, caused by the introduction of the microvascular canal into glass fiber reinforced plastic, on stress concentration and stress distribution during the failure of composites with two types of stacking $[0 / 90]_{4 \mathrm{~s}}$ and $[90 / 0]_{4 \mathrm{~s}}$. Experimental studies, demonstrating a significant strain concentration in the vicinity of an embedded optical fiber are described in $[12,13]$.

Aside from the issues related to the influence of embedded optical fibers on the host material, the problem of reliable strain measurements is of utmost importance. The study of the strain transfer from the host material to the embedded optical fiber with the use of strain transfer matrix is performed in [14]. Also it is known that the reflected optical signal of fiber-optic sensors based on Bragg gratings is distorted under transverse loads [15-18] and non-uniform strain distribution along the length of the grating [19-21]. The problem of reliable strain measurements by the embedded optical fibers, questions of how to choose the model linking the strain of the optical fiber in the area of the fiber Bragg grating with the measurement of its resonant wavelength and calibration problem as well as particular practical problems of measuring strains in composite materials with fiber-optic strain sensors are discussed in [22-25].

Most of the known studies focus on the problems that arise when optical fibers are embedded in layered composite materials with a unidirectional reinforcement structure. For such materials, the fact of dependence of appearance and dimensions of the resin pocket on the orientation of the embedded optical fiber with respect to the direction of reinforcing fibers is well known and experimentally verified. However, there is an insufficient number in studies concerning the incorporation of optical fibers into composite materials having other than unidirectional reinforcement structure. In this paper, layered composite materials with a woven reinforcement structure were studied. The introduction of such a foreign object as an optical fiber between the layers of this type of composite materials can have a significantly different effect on the distortion of adjacent layers in the region of the optical fiber due to a different internal structure. In the framework of the work, glass fiber reinforced plastic (GFRP) and carbon fiber reinforced plastic (CFRP) samples with embedded optical fibers were made. Using a digital microscope, cross-sectional images of the fabricated samples were obtained, which made it possible to analyze the structural distortions of the considered types of composite materials due to the embedded optical fiber and to evaluate whether a resin pocket technological defect occurs. Different kinds of sensors are based on the fiber-optic technology and are widely used in structural health monitoring [26]. In this study fiber-optic sensors (FOS) based on the fiber Bragg gratings (FBG) were used and the reflected optical signal from embedded sensors was analyzed.

\section{MANUFACTURING OF COMPOSITE MATERIAL WITH EMBEDDED OPTICAL FIBERS}

7 he process of creating products from polymer composite materials (PCM) includes several basic steps: laying out a reinforcing material in the specialized form, package assembly, the polymerization process and removal of manufactured sample. These technological steps are common for every manufacturing technique with some additional features depending on the particular process.

For the present study a woven fabric with weave style $2 \times 2$ twill was chosen as the reinforcement material. The weaving pattern is shown in the Fig. 1. The specimens were made with the help of compression molding manufacturing technique which allows to control the entire process and to achieve composite parts with uniform thickness. 


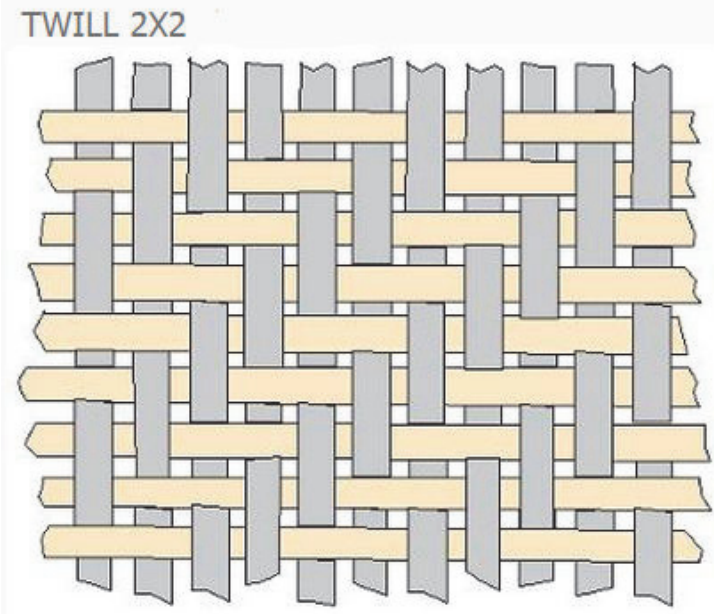

Figure 1: The scheme of the woven fabric $(2 \times 2$ twill) [27].

Creation of a smart material, such as a polymer composite material with embedded optical fibers, requires ensuring the optical fiber integrity during the material manufacturing process, as well as strict adherence to all process parameters such as pressure, temperature and time, depending on the brand of material. The following steps were carried out according to the manufacturing technological process and the process of FOS embedding into PCM. At the first step, the cutting of the reinforcing material on the plotter Zund G3 L-2500 was carried out. After that, the layers of reinforcing material were laid out on special form-building equipment. The stack of layers for both materials (glass-fiber reinforced plastic and carbon fiber-reinforced plastic) consisted of 20 layers. Optical fibers, made from silica glass core and cladding with diameter of $0.124 \mathrm{~mm}$ and polyimide protective coating with thickness of $0.012 \mathrm{~mm}$ were embedded between $10^{\text {th }}$ and $11^{\text {th }}$ layers of composite material (Fig. 2). In order to align optical fiber in a straight line, small tension was applied. It should be noted that the most dangerous areas for optical fiber, embedded in composite material, are the input and output areas and to ensure its integrity, optical fiber was encapsulated into the Teflon tube in these zones. After performing all the operations mentioned above, the polymerization process was carried out in the Langzauner press. During the polymerization process, control of pressure and temperature was carried out by a control computer. After that, the technological package was removed. The recommended regime, according to the specifications of the materials, for the curing process is shown in Fig. 3 [28].

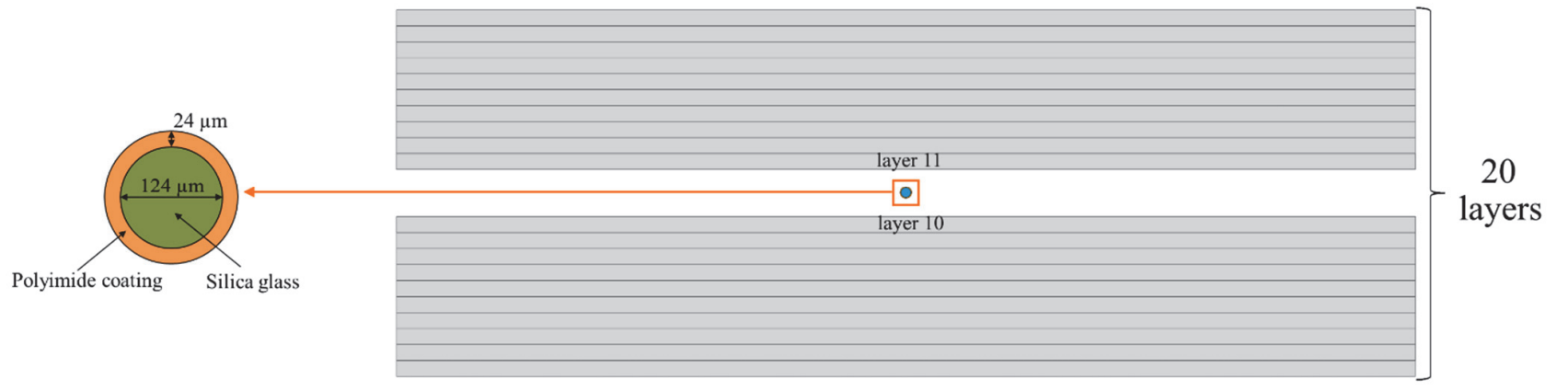

Figure 2: The scheme of optical fiber placement between layers of the composite material.

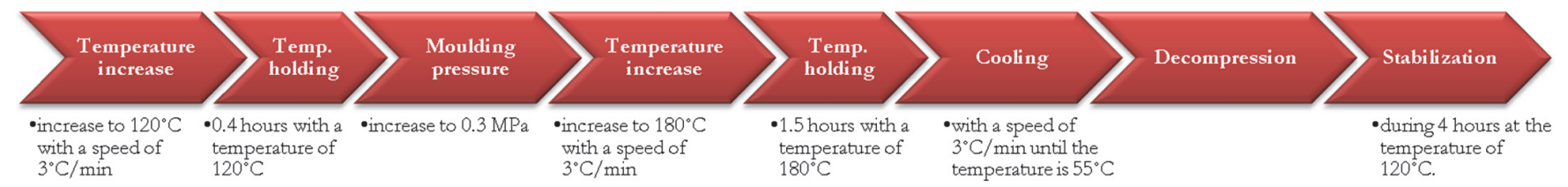

Figure 3: The recommended regime for the curing process. 
After the manufacturing process described above, the resulting plates were cut into individual specimens and the performance of embedded Bragg grating sensors was checked.

\section{FBG SPECTRA AFTER MANUFACTURING PROCESS}

$\mathrm{F}$

iber-optic sensors based on fiber Bragg gratings (FBG) embedded into material can give a lot of useful information about the mechanical state of the controlled object during its life cycle. This means that it is possible to measure such parameters as strain and temperature not only during operation but also during the manufacturing stage, which provides addition control measure for such complex materials as layered reinforced composites. Also, a highdensity mesh of controlled points can be established in the object of study due to the simplicity of multiplexing of FBGs in optical fiber, which means that a large number of gratings can be written and simultaneously interrogated in the single optical fiber.

The principle of FBG operation, illustrated in the Fig. 4, is based on sending the broadband optical signal through the core of the optical fiber and measuring the reflected from the grating narrowband part of the initial optical signal which is centered on the so-called Bragg wavelength. The Bragg wavelength in the initial unloaded state depends on the effective refractive index of the core of the optical fiber and grating period. Under load, such as strain or temperature change, the reflected spectrum shifts and therefore the Bragg wavelength changes, and this change can be used to calculate the strain or temperature in the FBG area.

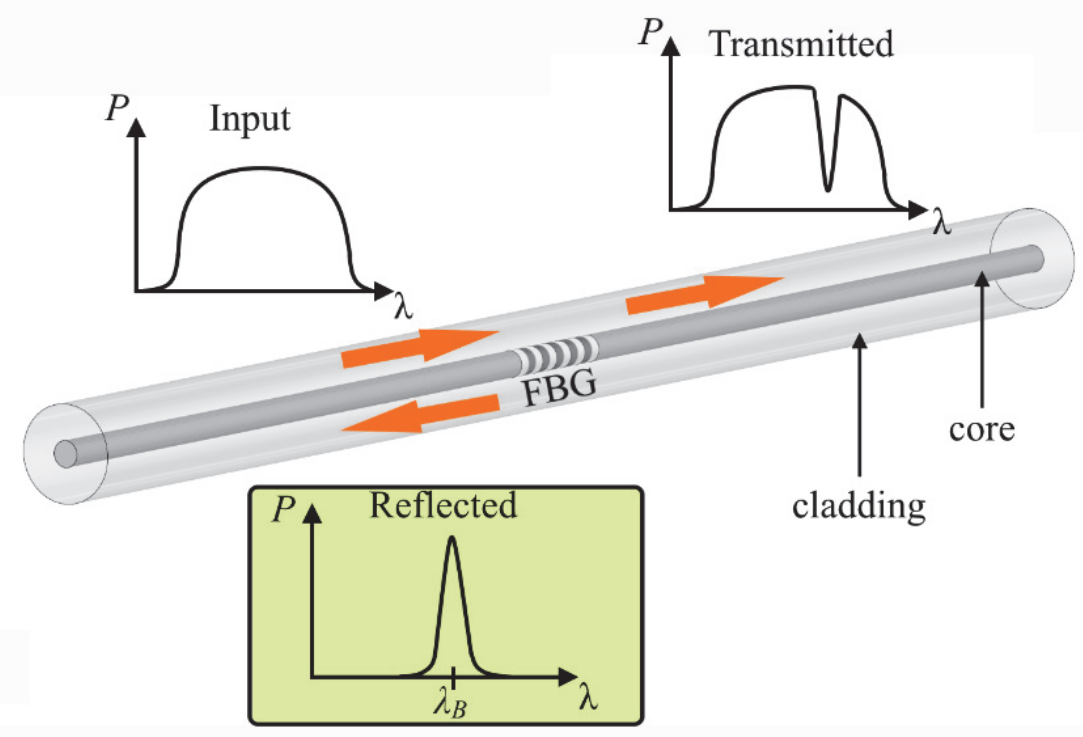

Figure 4: The principle of FBG operation.

The reflected spectrum in case of FBG written in low birefringence single mode optical fiber and operating in close to uniaxial stress state has only one peak value which can be easily detected. But it is known that when optical fiber in the Bragg grating area experience high transverse strains or strain gradient along the grating, the spectrum becomes distorted due to induced birefringence. In this case several peaks can occur for the single FBG and under loading the maximum value can jump from one peak to another. So, it becomes problematic to measure the Bragg wavelength shift and such situation can lead to significant measurement errors.

Manufacturing of composite materials is a complex technological process during which the constituents are exposed to severe external loads such as pressure and temperature. And the optical fiber, which is confined between the layers of composite material, experience these external loadings too. For the woven GFRP material, manufactured by the technological process described in the previous section, the specimen before the cutting contained an embedded optical fiber with 5 FBGs (Fig. 5). 


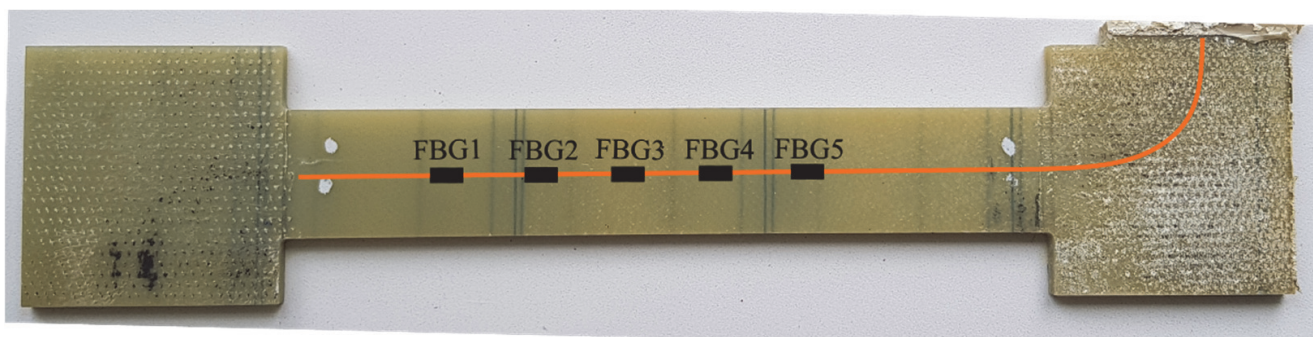

Figure 5: GFRP specimen with embedded FBGs.

Fiber-optic sensor readings from this specimen where analyzed after the manufacturing stage without any additional external forces applied. Bragg wavelengths of FBGs were spaced out in the range $1500-1600$ nm to not interfere with each other and the general spectrum is presented in Fig. 6.

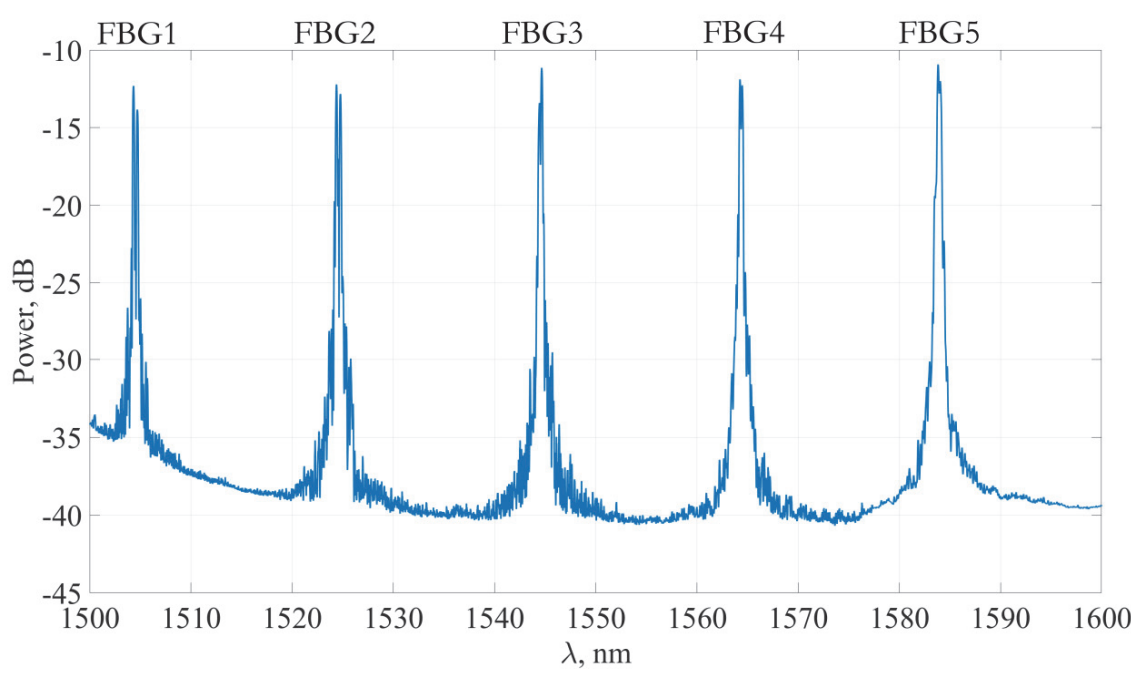

Figure 6: Reflected spectrum of 5 FBGs embedded in the GFRP specimen.

During the manufacture of composite material, optical fiber didn't lose its integrity and all FBGs are clearly distinguishable on the reflected spectrum. But a close analysis of reflected optical signal from each FBG, presented in Fig. 7, shows that the spectrum became highly distorted after the applied technological process.
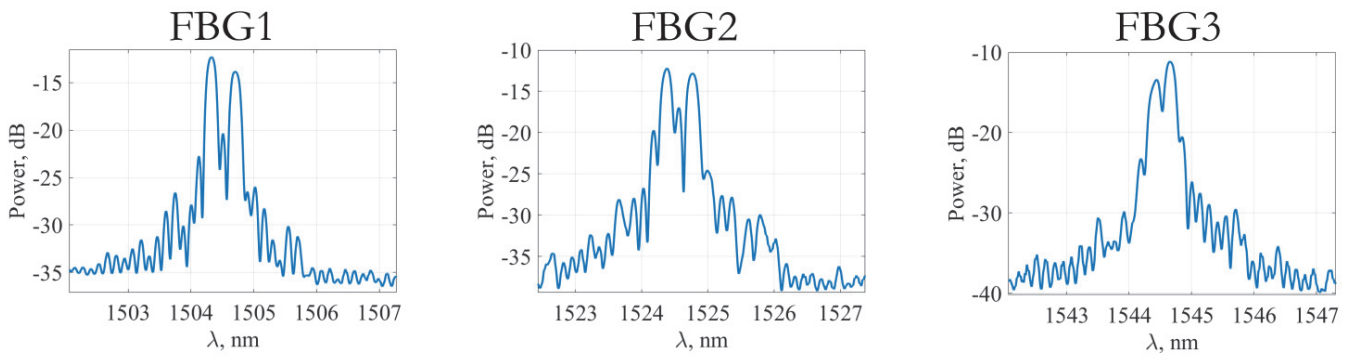

FBG4
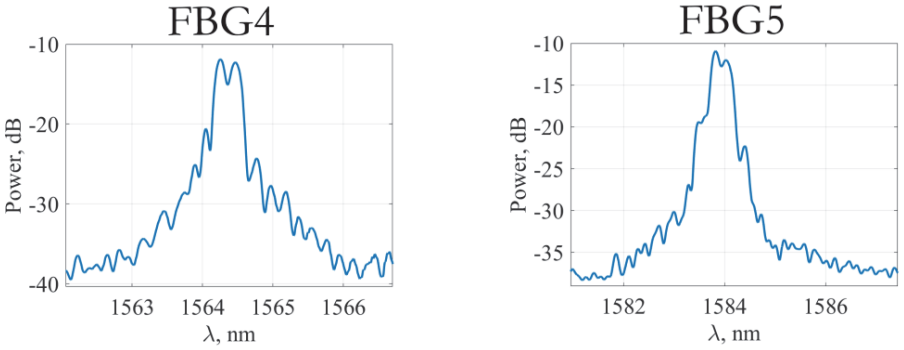

Figure 7: Reflected spectra for each FBG embedded in GFRP specimen. 
For all FBGs the split of the reflected spectrum is observed. As the peak values are close to each other it is difficult to detect the initial Bragg wavelength, relative to which the wavelength shift will be calculated. Also application of the most popular algorithm of Bragg wavelength detection, based on measuring the maximum value of the spectrum can lead to significant measurement errors because the maximum value can shift from one peak to another under loading. For studied case the biggest distance between two separated peaks is observed for the FBG2 and is $0.39 \mathrm{~nm}$, which can lead to strain measurement error of $327 \mu \varepsilon$ that is unacceptable for most practical cases. A similar situation was observed for CFRP specimen.

The obtained results on the distortion of the reflected optical signal from FBG sensors embedded into composite materials with a woven reinforcement structure are consistent with well-known studies for unidirectional composites $[18,29,30]$. This result shows that this problem is common for different types of composite materials and types of reinforcement. Spectral distortions can be caused by curing pressure, which leads to residual transverse strains of the optical fiber, and/or the non-uniform strain distribution along the length of the optical fiber that also occurs during the manufacturing process. There are several ways to overcome such problem, among which are the implementation of more advanced algorithms of calculating the spectrum change [31] and the use of additional mechanical protection of the Bragg grating area [32].

\section{ANALYSIS OF MICROSCOPIC IMAGES OF COMPOSITE SAMPLES WITH EMBEDDED OPTICAL FIBER}

o study the internal structure of the composite material with an embedded optical fiber, fiberglass and carbon fiber samples were cut into pieces using a round cutter. For each of the materials, 10 cross-sectional elements were investigated. The photos of the GFRP and CFRP samples intended for the microscopic analysis are shown in the

Fig. 8 .

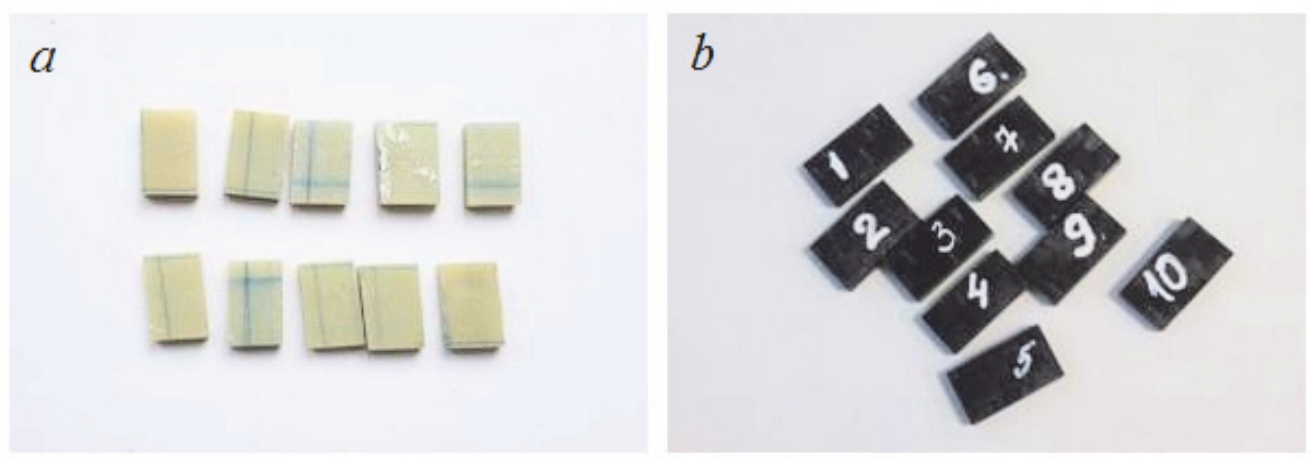

Figure 8: GFRP (a) and CFRP (b) samples.

In order to assess which type of surface is most suitable for study with an optical microscope, one cross sectional surface of each sample was polished, and one left in its original state after the cutting (Fig. 9).

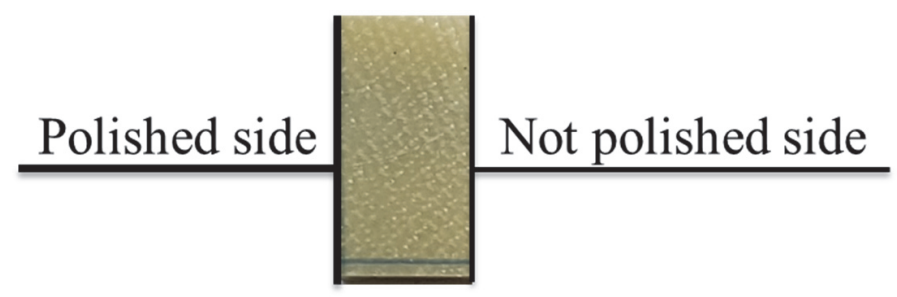

Figure 9: Surface treatment of samples.

The experiment was carried out with the help of microscope KH-7700 (Fig. 10), which allows to achieve a magnification up to $7000 \mathrm{x}$. In the experiment an MX (F) -10C lens with an OL-140 adapter and possible magnification up to 140x, 280x, 420x, 560x, 700x was used. 

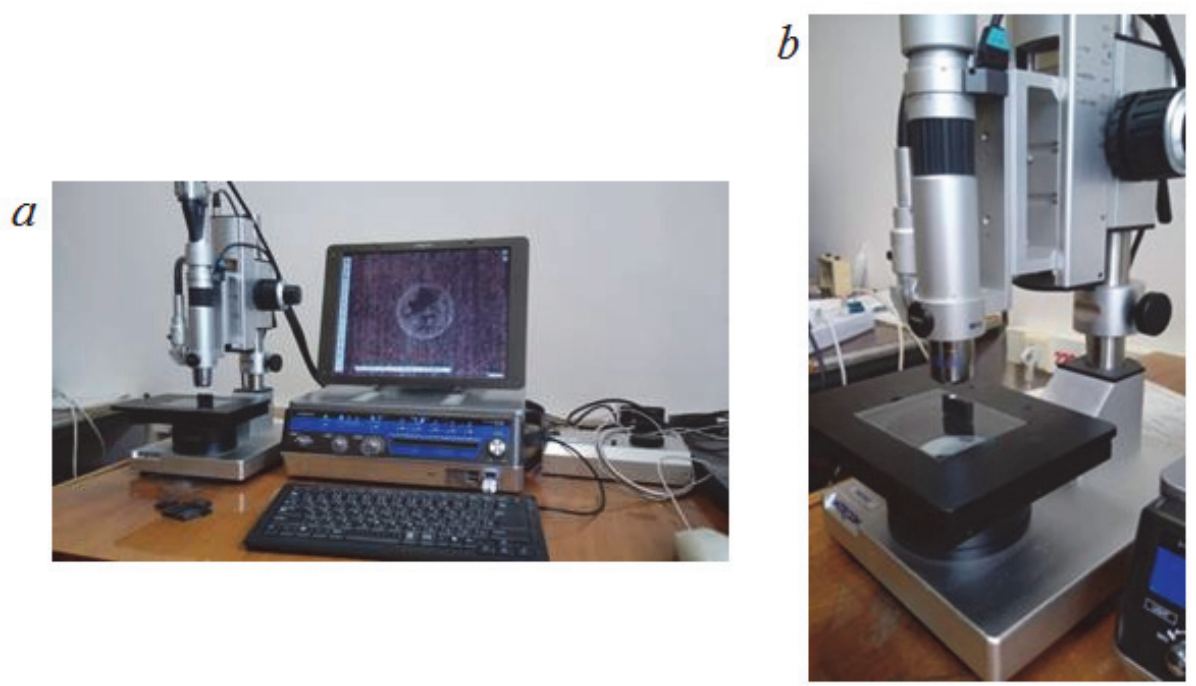

Figure 10: General view of the experimental setup (a), microscope (b).

In the Fig. 11 images of polished and unpolished surfaces of a GFRP samples with a 140-times magnification are shown.
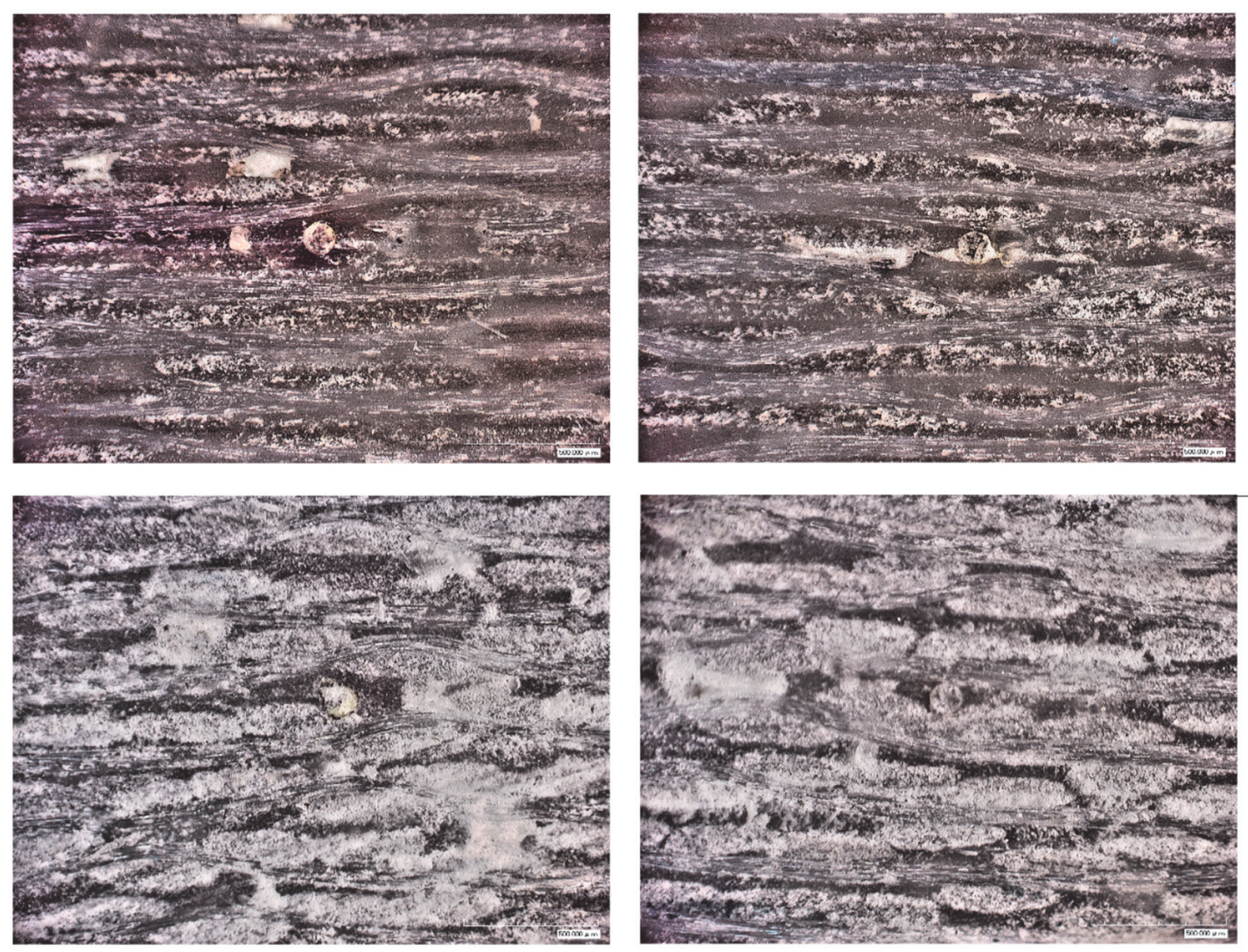

Figure 11: Microscopic images of GFRP samples with embedded optical fiber and different surface treatments: polished (upper row), not polished (lower row).

For this type of material, surface treatment leads to certain advantages and disadvantages. Thus, an embedded optical fiber is more clearly detected on a polished surface, however, a color gradient is less noticeable when moving from one phase of the composite material to another, which makes it difficult to identify the internal structure. Due to the large differences in height, there are problems with focusing the microscope on an untreated surface and it is not possible to 
obtain a clear image on a number of samples. However, on this type of surface different constituents of the composite material have more clearly distinguishable boundaries.

The analysis of the obtained images shows that on the GFRP samples such structural elements of the composite material with a woven reinforcement type as the warp and weft fibers and areas filled with resin are clearly identifiable (Fig. 12).

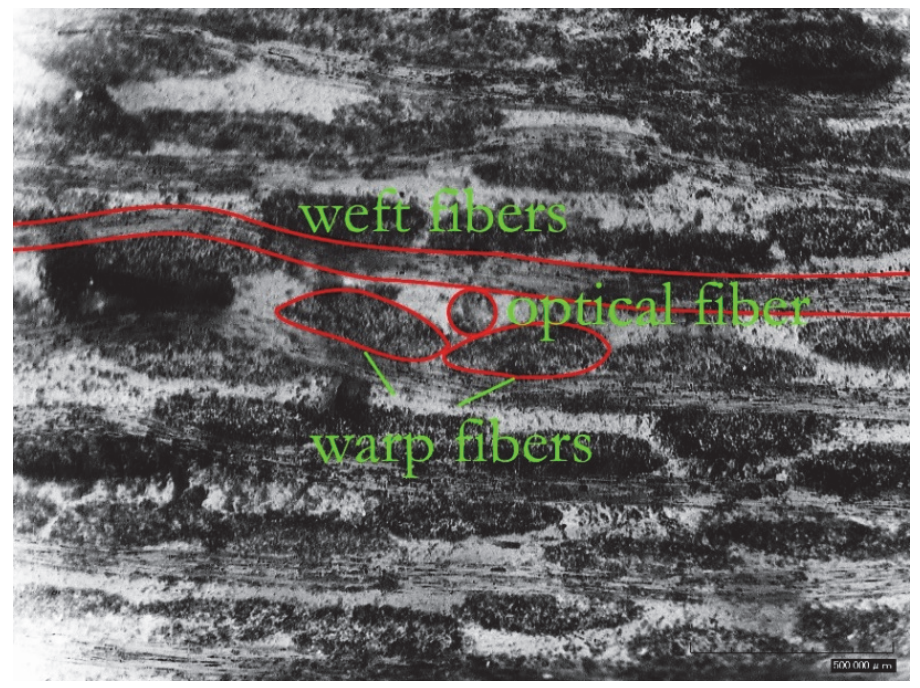

Figure 12: Image of the internal structure of GFRP sample with woven reinforcement scheme and embedded optical fiber.
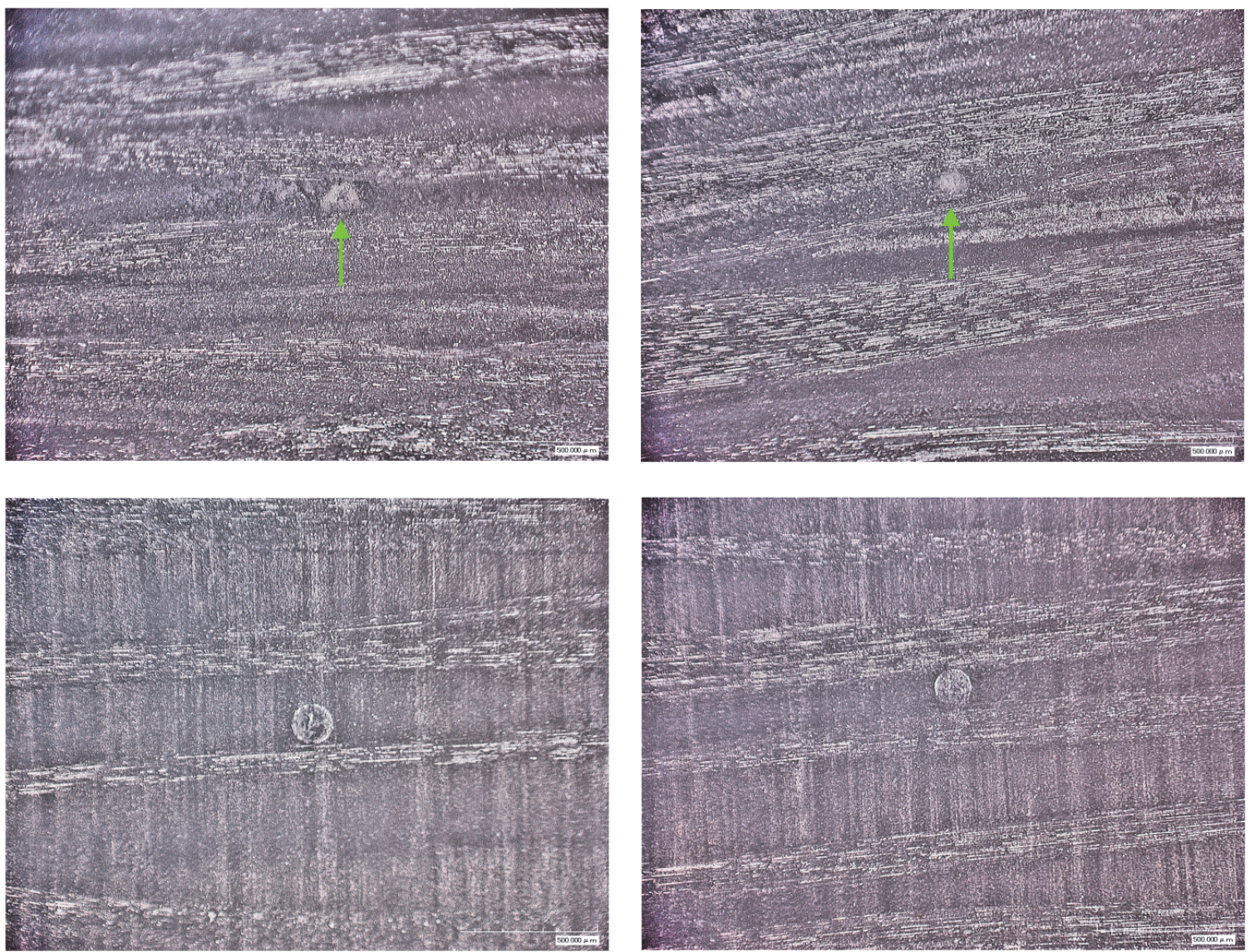

Figure 13: Images of the internal structure of a CFRP samples with embedded optical fiber and different surface treatments: not polished (upper row), polished (lower row). 
Despite the fact that optical fiber lies in resin rich region, only an insignificant distortion of the internal structure of the material in the area of the embedded optical fiber without the formation of a resin pocket, for all studied samples of GFRP, was found.

The microscopic images of CFRP samples for polished and unpolished surfaces are presented in the Fig. 13.

Due to a number of differences between carbon fibers and glass fibers (physico-mechanical properties, fiber size and density, etc.), a composite with carbon fiber reinforcement has a more ordered structure, in which, using an optical microscope, it was not possible to isolate individual warp fibers, only the weft fibers. In this case, the advantage of polishing the surface is clearly expressed, since in the absence of surface treatment the optical fiber is weakly or not at all distinguishable. In the obtained images, it was not possible to trace the distortions of the internal structure of the woven laminated composite material in the region of the embedded optical fiber.

The presence of a resin pocket in the area of embedded optical fiber is common for unidirectional composite materials and is a potential source of cracking and delamination. The absence of signs of a resin pocket formation for the considered composite materials with a woven reinforcement structure, obtained in the present study points at differences in the interaction of the internal structure of the composite materials and the embedded optical fiber. A possible explanation is that unlike unidirectional reinforced layers, which are bent around embedded optical fiber in case when the reinforcement direction is perpendicular to the optical fiber, the individual weft and warp fibers of woven structure provide more space for the optical fiber to be more efficiently integrated into the structure of the composite material.

\section{CONCLUSIONS}

$\mathrm{T}$ he present work is devoted to the study of the influence of embedded optical fibers on the internal structure of composite materials. One of the main goals was to expand knowledge on this problem for various types of composite materials. Unlike known studies, devoted to the materials with a unidirectional reinforcement structure, two types of composite material (GFRP and CFRP) with woven reinforcement structure and with embedded fiber-optic sensors based on Bragg gratings were studied.

The evaluation of the readings of Bragg grating sensors embedded into composite material revealed that the reflected spectrum has distortions due to manufacturing process that can lead to significant errors in the measurements of strain. This result indicates the need for additional mechanical protection of FBG when embedded in a composite material, which will allow avoiding strong distortions of the reflected signal during the manufacturing stage, or to use the more advanced methods for determining the Bragg wavelength shift, taking into account the shape of the spectrum.

Cross-sectional images of studied polymer composite materials with different types of surface treatments were analysed for structural changes due to the embedded optical fibers. Polishing of the studied surface makes it possible to more clearly distinguish the location of the optical fiber in the structure of the composite material, however, for the case of glass fiber, the visibility of the structural components of the composite deteriorates. For carbon fiber composite samples without polishing, it is almost impossible to detect optical fiber. However, for studied materials, analysing both polished and unpolished surfaces provides more complete information about the internal structure of the material. An analysis of the structure did not reveal any significant distortion of the layers in the region of the embedded optical fiber and the formation of a resin pocket for the considered composite materials with a woven reinforcement structure.

The obtained results indicate that the use of embedded optical fibers is promising and feasible for assessing the mechanical state of structures made from composite materials. However, in order to build effective and reliable monitoring systems based on this technology, it is necessary to take into account such factors as the type and structure of the reinforcement of the composite material into which the optical fiber is embedded, the manufacturing process, possible distortions of the reflected optical signal, on the basis of which the measured physical quantities (strain, temperature) are determined.

\section{ACKNOWLEDGEMENTS}

he research was supported by RFBR (project No. 17-41-590684 r_ural_a). 


\section{REFERENCES}

[1] Roberts, S.S.J., Davidson, R. (1991). Mechanical properties of composite materials containing embedded fiber-optic sensors. In: Claus, R.O., Udd, E., (Eds.), Fiber Optic Smart Structures and Skins IV, 1588, pp. 326-341.

[2] Hadzic, R., John, S., Herszberg, I. (1999). Structural integrity analysis of embedded optical fibres in composite structures, Compos. Struct., 47(1-4), pp. 759-765, DOI: 10.1016/S0263-8223(00)00050-7.

[3] Jensen, D.W., Pascual, J., August, J.A. (1992). Performance of graphite/bismaleimide laminates with embedded optical fibers. I. Uniaxial tension, Smart Mater. Struct., 1(1), pp. 24-30, DOI: 10.1088/0964-1726/1/1/004.

[4] Surgeon, M., Wevers, M. (1999). Static and dynamic testing of a quasi-isotropic composite with embedded optical fibres, Compos. Part A Appl. Sci. Manuf., 30(3), pp. 317-324, DOI: 10.1016/S1359-835X(98)00117-1.

[5] Lee, D.C., Lee, J.J., Yun, S.J. (1995). The mechanical characteristics of smart composite structures with embedded optical fiber sensors, Compos. Struct., 32(1-4), pp. 39-50, DOI: 10.1016/0263-8223(95)00038-0.

[6] Silva, J.M.A., Devezas, T.C., Silva, A.P., Ferreira, J.A.M. (2005). Mechanical characterization of composites with embedded optical fibers, J. Compos. Mater., 39(14), pp. 1261-1281, DOI: 10.1177/0021998305050423.

[7] Dasgupta, A., Wan, Y., Sirkis, J.S. (1992). Prediction of resin pocket geometry for stress analysis of optical fibers embedded in laminated composites, Smart Mater. Struct., 1(2), pp. 101-107, DOI: 10.1088/0964-1726/1/2/001.

[8] Shivakumar, K., Emmanwori, L. (2004). Mechanics of Failure of Composite Laminates with an Embedded Fiber Optic Sensor, J. Compos. Mater., 38(8), pp. 669-680, DOI: 10.1177/0021998304042393.

[9] Lammens, N., Luyckx, G., Voet, E., Van Paepegem, W., Degrieck, J. (2015). Finite element prediction of resin pocket geometry around embedded optical fiber sensors in prepreg composites, Compos. Struct., 132, pp. 825-832, DOI: 10.1016/j.compstruct.2015.07.003.

[10] Shivakumar, K., Bhargava, A. (2005). Failure Mechanics of a Composite Laminate Embedded with a Fiber Optic Sensor, J. Compos. Mater. - J Compos MATER, 39(9), pp. 777-798, DOI: 10.1177/0021998305048156.

[11] Al-Shawk, A., Tanabi, H., Sabuncuoglu, B. (2018). Investigation of stress distributions in the resin rich region and failure behavior in glass fiber composites with microvascular channels under tensile loading, Compos. Struct., 192(February), pp. 101-114, DOI: 10.1016/j.compstruct.2018.02.061.

[12] Singh, H., Sirkis, J.S., Dasgupta, A. (1991).Microinteraction of optical fibers embedded in laminated composites. In: Claus, R.O., Udd, E., (Eds.), 1588, pp. 76-85.

[13] Czarnek, R., Guo, Y.F., Bennett, K.D., Claus, R.O. (1989).Interferometric Measurements Of Strain Concentrations Induced By An Optical Fiber Embedded In A Fiber Reinforced Composite. In: Udd, E., (Ed.), p. 43.

[14] Luyckx, G., Voet, E., DeWaele, W., Degrieck, J. (2010). Multi-axial strain transfer from laminated CFRP composites to embedded Bragg sensor: I. Parametric study, Smart Mater. Struct., 19(10), DOI: 10.1088/0964-1726/19/10/105017.

[15] Wagreich, R.B., Atia, W.A., Singh, H., Sirkis, J.S. (1996). Effects of diametric load on fibre Bragg gratings fabricated in low birefringent fibre, Electron. Lett., 32(13), pp. 1223, DOI: 10.1049/el:19960806.

[16] Udd, E. (2007). Review of multi-parameter fiber grating sensors, Fiber Opt. Sensors Appl. V, 6770, pp. 677002, DOI: $10.1117 / 12.753525$.

[17] Gafsi, R., El-Sherif, M.A. (2000). Analysis of Induced-Birefringence Effects on Fiber Bragg Gratings, Opt. Fiber Technol., 6(3), pp. 299-323, DOI: 10.1006/ofte.2000.0333.

[18] Emmons, M.C., Carman, G.P., Mohanchandra, K.P., Richards, W.L. (2009).Characterization and birefringence effect on embedded optical fiber Bragg gratings. In: Kundu, T., (Ed.), Health Monitoring of Structural and Biological Systems 2009, 7295, p. 72950C.

[19] Peters, K., Pattis, P., Botsis, J., Giaccari, P. (2000). Experimental verification of response of embedded optical fiber Bragg grating sensors in non-homogeneous strain fields, Opt. Lasers Eng., 33(2), pp. 107-119,

DOI: $10.1016 / \mathrm{S} 0143-8166(00) 00033-6$.

[20] Peters, K., Studer, M., Botsis, J., Iocco, A., Limberger, H., Salathé, R. (2001). Embeded optical fiber bragg grating sensor in a nonuniform strain field: Measurements and simulations, Exp. Mech., 41(1), pp. 19-28, DOI: $10.1007 / \mathrm{BF} 02323100$.

[21] Huang, S., Ohn, M.M., LeBlanc, M., Measures, R.M. (1998). Continuous arbitrary strain profile measurements with fiber Bragg gratings, Smart Mater. Struct., 7(2), pp. 248-256, DOI: 10.1088/0964-1726/7/2/012.

[22] Makhsidov, V., Fedotov, M., Shiyonok, A., Zuev, M. (2014). For an issue of embedded optical fibre in CFRP and strain measurement with fibre Bragg gratings sensors, J. Compos. Mech. Des., 20(4), pp. 568-574.

[23] Majumder, M., Gangopadhyay, T.K., Chakraborty, A.K., Dasgupta, K., Bhattacharya, D.K. (2008). Fibre Bragg gratings in structural health monitoring-Present status and applications, Sensors Actuators, A Phys., pp. 150-164, 
DOI: $10.1016 /$ j.sna.2008.04.008.

[24] Gebremichael, Y.M., Li, W., Boyle, W.J.O., Meggitt, B.T., Grattan, K.T. V., McKinley, B., Fernando, G.F., Kister, G., Winter, D., Canning, L., Luke, S. (2005). Integration and assessment of fibre Bragg grating sensors in an all-fibre reinforced polymer composite road bridge, Sensors Actuators, A Phys., 118(1), pp. 78-85, DOI: $10.1016 /$ j.sna.2004.08.005.

[25] Matveenko, V.P., Shardakov, I.N., Voronkov, A.A., Kosheleva, N.A., Lobanov, D.S., Serovaev, G.S., Spaskova, E.M., Shipunov, G.S. (2018). Measurement of strains by optical fiber Bragg grating sensors embedded into polymer composite material, Struct. Control Heal. Monit., 25(3), DOI: 10.1002/stc.2118.

[26] Di Sante, R. (2015). Fibre Optic Sensors for Structural Health Monitoring of Aircraft Composite Structures: Recent Advances and Applications., Sensors, 15(8), pp. 18666-18713, DOI: 10.3390/s150818666.

[27] Apostolakis, D. Apostolakis, D.(2019). Fibermax composites: Weaving styles.

[28] Matveenko, V.P., Kosheleva, N.A., Shardakov, I.N., Voronkov, A.A. (2018). Temperature and strain registration by fibre-optic strain sensor in the polymer composite materials manufacturing, Int. J. Smart Nano Mater., 9(2), pp. 99110, DOI: 10.1080/19475411.2018.1450791.

[29] Voet, E., Luyckx, G., De Waele, W., Degrieck, J. (2010). Multi-axial strain transfer from laminated CFRP composites to embedded Bragg sensor: II. Experimental validation, Smart Mater. Struct., 19(10), pp. 105018, DOI: $10.1088 / 0964-1726 / 19 / 10 / 105018$.

[30] Luyckx, G., Voet, E., Lammens, N., De Waele, W., Degrieck, J. (2013). Residual strain-induced birefringent FBGs for multi-axial strain monitoring of CFRP composite laminates, NDT E Int., 54, pp. 142-150, DOI: 10.1016/j.ndteint.2012.11.008.

[31] Tosi, D. (2017). Review and analysis of peak tracking techniques for fiber bragg grating sensors, Sensors (Switzerland), 17(10), DOI: $10.3390 /$ s17102368.

[32] Kosheleva, N., Matveenko, V., Serovaev, G., Fedorov, A. (2019). Numerical analysis of the strain values obtained by FBG embedded in a composite material using assumptions about uniaxial stress state of the optical fiber and capillary on the Bragg grating, Frat. Ed Integrità Strutt., 13(49), pp. 177-189, DOI: 10.3221/IGF-ESIS.49.19. 